\title{
Projetos de leitura e escrita literária para uma educação antirracista: estudando história em quadrinhos e cordel com o sexto ano do Ensino Fundamental
}

\begin{abstract}
Resumo:
Este artigo apresenta alguns dos paradigmas teóricos (SILVA, 2007, 2015; GOMES, 2012; entre outros) e descreve algumas das práticas pedagógicas que compuseram um projeto de leitura e de escrita literária desenvolvido com turmas de sexto ano. Enquanto docentes de Literatura e de Língua Portuguesa, assumimos compromisso com a educação literária e linguística e, por isso, tornamos o texto, o ler e os e as estudantes o centro de nossas práticas. Objetivando explicitar tal perspectiva, apresentamos, aqui, fragmentos do projeto "Minha Cor, Tua Cor, Todas as Cores", o qual se compromete especialmente com a educação para as relações étnico-raciais, mas também com a formação de leitores e de leitoras de literatura, de arte, de quadrinhos e do mundo. Um projeto de leitura com esse perfil transita entre os saberes, convocando diversas áreas do conhecimento: do currículo à sociologia; das artes à teoria da literatura; da sociologia à educação.
\end{abstract}

\section{Palavras-chave:}

Projeto de leitura. Educação literária. Educação antirracista. História em quadrinhos. Literatura de cordel.

\begin{abstract}
:
This article presents some of the theoretical paradigms (SILVA, 2007, 2015; GOMES, 2012; among others) and describes some of the pedagogical practices that were part of a literary reading and writing project developed with sixth grade groups. As teachers of Literature and Portuguese Language, we are committed to literary and linguistic education and, therefore, we make the text, the reading process, and the students the center of our practices. In order to make this perspective explicit, we present here fragments of the project "Minha Cor, Tua Cor, Todas as Cores", which is especially committed to the education for ethnic-racial relations, but also the development of readers of literature, art, comic books and the world. A reading project with these characteristics traverses different areas of knowledge: from curriculum to sociology; from the arts to the theory of literature; from sociology to education.
\end{abstract}

\section{Keywords:}

Reading project. Literary education. Anti-racist education. Comic books. Cordel literature.

\footnotetext{
* Doutora em Teoria da Literatura (PUCRS), professora de Literatura e Língua Portuguesa do Colégio de Aplicação da Universidade do Rio Grande do Sul, instituição na qual desenvolve o projeto de pesquisa "O livro é um convite: projetos de leitura e formação de leitores na Educação Básica" e o programa de extensão "Práticas pedagógicas do CAp em diálogo". E-mail: carol.valada@gmail.com. ORCID iD: https://orcid.org/0000-0002-6088-1626.

** Doutorando em Letras - Estudos da Linguagem (UFRGS), professor de Língua Portuguesa do município de Sapucaia do Sul (RS). E-mail: samuelgdo@gmail.com. ORCID iD: https://orcid.org/0000-0002-1660-3354.
} 


\section{Introdução}

Na primeira página do livro Pequeno Manual Antirracista, Djamila Ribeiro (2019, p. 7) traz estas palavras: "Quando criança, fui ensinada que a população negra havia sido escravizada e ponto, como se não tivesse existido uma vida anterior nas regiões de onde essas pessoas foram tiradas à força”. Tal testemunho, organizado em uma breve frase, remete-nos à escola, a instâncias de poder, a inscrições identitárias e, por fim, à falácia da democracia racial.

A instituição escola é espécie de travessia, um caminho entre a casa e o mundo: uma escola é construída por pessoas - as quais carregam e demonstram (por meio da linguagem e de ações) saberes, crenças, ideologias. A escola, portanto, não se dissocia da sociedade: na verdade, muitas vezes, reproduz, na sala de aula, nos corredores e no pátio, modos de se relacionar dissipados no mundo. A partir dessa constatação, podemos dizer que o racismo estrutural presente no Brasil, infelizmente, tem eco na dinâmica escolar.

E para que serve a escola?

A partir dos objetivos do Ensino Fundamental elencados desde os Parâmetros Curriculares Nacionais (BRASIL, 1998), a escola deve formar estudantes capazes de participar social e politicamente na sociedade, posicionando-se de maneira crítica, responsável e construtiva para questionar a realidade e resolver problemas. Para Simões et al. (2012), a escola forma cidadãos, sujeitos que lidam de maneira segura com a complexidade do mundo e que nele intervêm de maneira criativa, o que exige a compreensão de que as relações humanas são complexas, diversas, situadas e historicamente construídas. Tendo isso em vista, entendemos que o estudo das relações étnico-raciais na educação básica é mais do que uma possibilidade: trata-se de uma necessidade, de um compromisso político.

Considerando nosso papel como educadores e educadoras, apresentamos, a seguir, algumas reflexões teóricas e propostas pedagógicas. O caminho de nossa escrita inicia com uma reflexão sobre o lugar da Educação para as Relações Étnico-Raciais (ERER) no currículo da Educação Básica. Em seguida, apresentamos uma proposta de projeto de leitura e escrita literária comprometido com a ERER, do qual destacamos o trabalho com dois gêneros do discurso: quadrinhos e cordel. Ao apresentar possibilidades de trabalho em Língua Portuguesa e Literatura que adotam uma atitude interdisciplinar ao abordarem as relações étnico-raciais, esperamos fomentar debates sobre um ensino comprometido com a democracia, com a ética antirracista e com a emancipação dos sujeitos.

\section{Currículo e relações étnico-raciais na Educação Básica}

Embora todo cidadão e toda cidadã deva, com criticidade, refletir e, então, assumir uma postura antirracista, a escola (logo, a construção curricular) - tempo e espaço de formação - tem o dever ético (e também jurídico ${ }^{1}$ ) de promover um fazer pedagógico comprometido com o respeito e com a valorização das diferentes etnias, identidades e historicidades. Afinal, “[u]m ensino que valorize as várias existências e que referencie positivamente a população negra é benéfico para toda a sociedade” (RIBEIRO, 2019, p. 41).

No texto "Aprender, ensinar e relações étnico-raciais no Brasil”, a professora e pesquisadora Petronilha Beatriz Gonçalves e Silva (2007, p. 490, grifos nossos) explica que a educação das relações étnico-raciais

\footnotetext{
1. “A Lei no 10.639/2003 altera a Lei no 9.394/1996 das Diretrizes e Bases da Educação Nacional, introduzindo a obrigatoriedade do ensino de história e cultura afro-brasileira e africana, bem como determinando que nas escolas se celebre o dia 20 de novembro, dia da Consciência Negra. A Lei no 11.645/2008 altera o artigo 26 da Lei de Diretrizes e Bases, acrescentando a obrigatoriedade do ensino de história e cultura dos povos indígenas. Ver também a Lei no 12.288/2010, que institui o Estatuto da Igualdade Racial, bem como a Lei $n \cong 12.711 / 2012$, conhecida como Lei das Cotas, para o ensino superior" (SILVA, 2015, p. 162).
} 
[...] tem por alvo a formação de cidadãos, mulheres e homens empenhados em promover condições de igualdade no exercício de direitos sociais, políticos, econômicos, dos direitos de ser, viver, pensar, próprios aos diferentes pertencimentos étnico-raciais e sociais. Em outras palavras, persegue o objetivo precípuo de desencadear aprendizagens e ensinos em que se efetive participação no espaço público. Isto é, em que se formem homens e mulheres comprometidos com e na discussão de questões de interesse geral, sendo capazes de reconhecer e valorizar visões de mundo, experiências históricas, contribuições dos diferentes povos que têm formado a nação, bem como de negociar prioridades, coordenando diferentes interesses, propósitos, desejos, além de propor políticas que contemplem efetivamente a todos.

Em outras palavras, a ERER está profundamente relacionada à democracia e à equidade, abandonando visões eurocêntricas, etnocêntricas e racistas (e poderíamos acrescentar, também, autoritárias e sexistas). Ainda segundo a autora, podemos assumir três paradigmáticos objetivos orientadores da ERER: a busca pela consciência política e histórica da diversidade; o fortalecimento de identidades e de direitos; a proposição de ações de combate ao racismo e a discriminações (SILVA, 2007, p. 491).

As intenções inerentes à ERER vinculam-se, inevitavelmente, às concepções de currículo, o qual “estabelece diferenças, constrói hierarquias, produz identidades” (SILVA, 1999, p. 12). Isso significa que a elaboração curricular convoca e, ao mesmo tempo, desenha relações de poder, pois assume perspectivas, atribui valores e faz seleções (o que implica, por consequência, exclusões).

$\mathrm{Na}$ instituição escola, o currículo é um discurso (um artefato, uma superfície de inscrição) que forja e apresenta identidades. Ver o currículo como representação, para Silva (1999, p. 66), "implica expor e questionar os códigos, as convenções, a estilística, os artifícios por meio dos quais ele é produzido”. Em alguma medida, portanto, o currículo responde a estes questionamentos: O que se ensina? Quais são os critérios de seleção? O que se espera dos e das estudantes?

A organização curricular produz e cria significados sociais, o que pode resultar na negação e no silenciamento de certas vozes, como destaca Santomé (1995). Os discursos e práticas racistas, presentes no currículo escolar, são, para o autor, construídos como estratégia para justificar e reforçar os privilégios daqueles que ocupam posições dominantes. Essas constatações nos levam a reflexões acerca das identidades étnicas - logo, à ERER -, pois “o conhecimento sobre raça e etnia incorporado no currículo não pode ser separado daquilo que as crianças e os jovens se tornarão como seres sociais” (SILVA, 2005, p. 102). A educação das relações étnico-raciais principia, então, pelo currículo e pelo questionamento das narrativas hegemônicas, as quais vêm marcadas pela herança colonial.

A Lei $n^{\circ} 10.639 / 03$ e a ERER, portanto, não se organizam enquanto novo componente curricular, mas sim enquanto nova postura diante dos saberes e das práticas docentes (GOMES, 2012, p. 105). No texto "Relações étnico-raciais, educação e descolonização dos currículos", Nilma Lino Gomes explica ao leitor e à leitora as mudanças provocadas pela ERER:

[uma] ruptura epistemológica e curricular, na medida em que torna público e legítimo o "falar" sobre a questão afro-brasileira e africana. Mas não é qualquer tipo de fala. É a fala pautada no diálogo intercultural. E não é qualquer diálogo intercultural. É aquele que se propõe ser emancipatório no interior da escola, ou seja, que pressupõe e considera a existência de um "outro", conquanto sujeito ativo e concreto, com quem se fala e de quem se fala. E nesse sentido, incorpora conflitos, tensões e divergências. (GOMES, 2012, p. 105).

O excerto tece um potente resumo da discussão: na escola, falaremos sobre questões afro-brasileiras e africanas. Em alguma medida, isso sempre aconteceu, mas de que modo? Que narrativa histórica, por exemplo, foi apresentada aos e às estudantes durante muitos anos? Mais do que isso: Quais construções epistemológicas e que teóricos e teóricas, pensadores e pensadoras, levamos, ano após ano, para as escolas?

Para uma educação libertadora (FREIRE, 1987) e para uma pedagogia antimarginalização, é necessário, como aponta Santomé (1995), que as escolas proporcionem, mediante a prática cotidiana, análises de como e por que as discriminações surgem e que significados devem ter as diferenças coletivas e individuais. 
Conteúdos antirracistas não podem, para o autor, ficar reduzidos a temas esporádicos, marginais, independentes, a objetos de dias especiais ou a componentes curriculares específicos, práticas ainda observadas em muitas escolas.

De que maneira, então, nas aulas de Língua Portuguesa e Literatura podemos reestruturar o currículo, assumindo compromisso com a ERER? Certamente, a resposta é extensa e, diante de tantas possibilidades/necessidades, começamos pela análise da escolha do repertório de leitura literária. Ao observar a lista de livros disponíveis aos e às estudantes e ao analisar as leituras a serem realizadas com a turma toda, é possível encontrar as identidades negras representadas? Se sim, em qual proporcionalidade - isto é, nos livros apresentados, temos a mesma quantidade de personagens negras e brancas? Se há negros e negras representados e representadas nas obras, que representação é essa - isto é, ela desconstrói estereótipos e valoriza essas identidades?

Djamila Ribeiro explica o racismo estrutural por meio do campo artístico: "Um exemplo é a ausência de pessoas negras numa produção cinematográfica - aí também está o racismo" (RIBEIRO, 2019, p. 38). Deslocaremos a reflexão para o fazer literário e, para isso, buscaremos dois estudos: a pesquisa Personagens do romance brasileiro contemporâneo, organizada pela professora Regina Dalcastagnè (2005), e a tese de doutoramento da professora Gládis Kaercher (2006), intitulada O mundo na caixa: gênero e raça no Programa Nacional Biblioteca da Escola - 1999.

O estudo de Dalcastagnè, desenvolvido no início dos anos 2000, foi bastante significativo para pensarmos, no curso e na pós-graduação em Letras, sobre representação. Apresentando de modo muito sucinto, a pesquisa dedicou-se a analisar romances nacionais, publicados entre 1990 e 2004, verificando quais personagens desfilaram pelas histórias - Haveria negros e negras? Mulheres e homens? Quais funções na narrativa eles e elas exercem? Por meio de um estudo quantitativo, a professora e demais pesquisadores e pesquisadoras envolvidos e envolvidas evidenciaram um dos aspectos de nossa sociedade: a desigualdade. No corpus literário analisado, identificaram que $70 \%$ dos protagonistas são homens; $80 \%$, heterossexuais; 79\%, brancos (DALCASTAGNÈ, 2005, p. 44).

E por que tais constatações relacionam-se à ERER? Simplesmente porque a Arte (e tantos outros discursos que circulam na sociedade) perpetua hierarquias, exclusões e valorações. Se a escola é o caminho entre a casa e a rua, quando levamos leituras literárias às crianças e aos e às jovens, apresentamos a eles e a elas representações da sociedade. Talvez a consciência sobre os problemas e traumas implicados nesse cenário seja novidade para os sujeitos brancos da nossa sociedade, contudo, para pessoas não brancas, certamente, todos esses atravessamentos marcaram suas vidas. É o que lemos no excerto abaixo, retirado da tese da professora Gládis Kaercher - trabalho que, justamente, se preocupa com as representações identitárias que a literatura faz circular:

Em nenhum dos mundos que eu visitava naquelas leituras eu me reconhecia: os personagens "belos e bons" nunca eram negros. Em uma tarde, recordo que percebi com clareza a primeira figura negra que eu vi em um livro infantil: chamava-se "tiquinho de carvão" e fazia parte de uma história contida na série $O$ mundo da criança: Tiquinho de carvão era feio, malévolo, não tinha família nem um final feliz. (KAERCHER, 2006, p. 20)

Por isso, os professores e as professoras de Língua Portuguesa e Literatura, ao indicarem leituras, devem comprometer-se com a ERER: devem analisar a construção de personagens nas obras, bem como a circulação de saberes e de ideias, tendo em vista a representatividade positiva de identidades negras. Esse compromisso também se associa a outra tarefa dos educadores e das educadoras de Língua Portuguesa e Literatura: a promoção do letramento dos e das estudantes, isto é, do uso da linguagem de maneira segura para a efetiva participação em diferentes práticas sociais e para a solução de problemas.

Simões et al. (2012) defendem a importância da adoção, na escola, de atitudes interdisciplinares, entendidas como o compromisso de fazer convergir, em prol da construção de conhecimentos significativos e da solução de problemas, múltiplos pontos de vista. As autoras consideram que as propostas interdisci- 
plinares dependem de cada contexto de ensino-aprendizagem e que, em Língua Portuguesa e Literatura, os projetos, mesmo que contenham objetivos disciplinares, podem ser construídos a partir de um eixo temático e de uma problematização interdisciplinar. Essa proposta de elaboração de projetos de ensino que façam convergir conhecimentos de diferentes disciplinas para a resolução de problemas da vida prática dos e das estudantes parece um caminho frutífero para um ensino comprometido com a ERER.

Diante do exposto, entender a escola como lugar de transformação da realidade nos parece essencial. Afinal, como nos ensina Petronilha Silva (2015, p. 169), "as escolas tanto podem favorecer relações de dominação, atualizar racismos, discriminações entre grupos e pessoas, como podem, se houver sincero empenho para tanto, reeducar no sentido do respeito, reconhecimento, valorização, convívio construtivo". Sabemos que precisamos reeducar e nos reeducar, descolonizar o currículo, democratizar as representações e diversificar os saberes. Assumindo tais compromissos, construímos um projeto de leitura e escrita literária chamado "Minha Cor, Tua Cor, Todas as Cores".

\section{"Minha Cor, Tua Cor, Todas as Cores": um projeto de leitura e de escrita literária comprometido com a ERER}

"Minha Cor, Tua Cor, Todas as Cores" foi um projeto idealizado por um grupo de professores brancos e de professoras brancas², atuantes no Colégio de Aplicação da UFRGS (instituição na qual o corpo docente é quase absolutamente formado por sujeitos não negros). Compreendendo nossas marcas identitárias, os atravessamentos da branquitude e a inegável estrutura social racista, nos dedicamos a desenhar práticas pedagógicas comprometidas com a ERER. Para isso, estudamos, lemos e ouvimos escritores e escritoras, pesquisadores e pesquisadoras não brancos e não brancas, sempre tentando exercitar a alteridade.

Mobilizando o referencial teórico acima exposto (perspectiva teórica, ética e política que tentamos assumir como paradigmática para nossa prática docente), compusemos um longo projeto de leitura e escrita literária para turmas de sexto ano, organizando-o em diferentes etapas, todas desenvolvidas em 2019. Para compor o repertório, tentamos: 1) eleger autores negros e autoras negras; 2) selecionar narrativas nas quais as representações de personagens negras fossem positivas; 3 ) abordar a autoestima e a valorização dos traços fenotípicos de sujeitos negros; 4) refletir acerca da estrutura racista em diferentes níveis; 5) apresentar narrativas de resistência e de força associadas a personalidades históricas; 6) transitar por diferentes criações culturais, passando pelas histórias em quadrinhos, pelo Cinema, pela Música, pelo cordel, pela linguagem da internet (com youtubers); 7) relacionar Literatura e Arte Visuais; 8) propor produções escritas que estivessem contextualizadas em situações de comunicação e que também incitassem a inscrição da subjetividade dos e das estudantes.

Um projeto de leitura literária organiza sequências de atividades a serem experienciadas a longo prazo: partindo de um eixo temático ou de algum aspecto em comum, docentes escolhem um ou mais livros a serem lidos pelos e pelas estudantes, deliberam sobre possíveis relações (com variadas linguagens, com diferentes componentes curriculares, com múltiplos saberes...) e planejam uma sequência de atividades (a qual pode sofrer alterações, inserindo ou suprimindo etapas). Um projeto de leitura literária pode acontecer ao longo de um ano letivo (como o projeto "Minha Cor, Tua Cor, Todas as Cores"), ao longo de um trimestre ou durante um mês: tudo dependerá dos objetivos estabelecidos, os quais são (devem ser) compartilhados com a turma.

Nossa proposta pedagógica dos projetos de leitura organiza-se a partir de algumas convicções ${ }^{3}$ : assume a escola como cenário; reconhece os e as estudantes como protagonistas; admite a leitura literária como ação central e aglutinadora; almeja democratizar a leitura literária e exercitar a alteridade; entende a interação pela linguagem como a realização de atividades discursivas, ou seja, práticas sociais desenvol-

2. Caroline Valada Becker, Samuel Gomes de Oliveira, Marcelo Gonçalves Maciel, Rosália Procasko Lacerda, Karine Storck.

3. Para tanto, nos baseamos em diversos autores e autoras, dos quais destacamos Simões et al. (2012) e Colomer (2007). 
vidas por sujeitos historicamente situados; mobiliza saberes da Teoria da Literatura e da Linguística de maneira contextualizada e à serviço dos gêneros do discurso em estudo; projeta atividades de leitura e de escrita baseadas nos pressupostos do letramento (e possibilita, assim, situações de comunicação autênticas); projeta diferentes situações a serem experienciadas pelos e pelas estudantes; promove comunidades de leitores; elege a intertextualidade e a interdisciplinaridade (inclusive a docência compartilhada) como alicerces.

Abaixo, sistematizamos uma linha do tempo com as ações do projeto "Minha Cor, Tua Cor, Todas as Cores"':

Figura 1 - Etapas do projeto de leitura

LEITURAS \& ATIVIDADES No PRIMERO TRIMESTRE
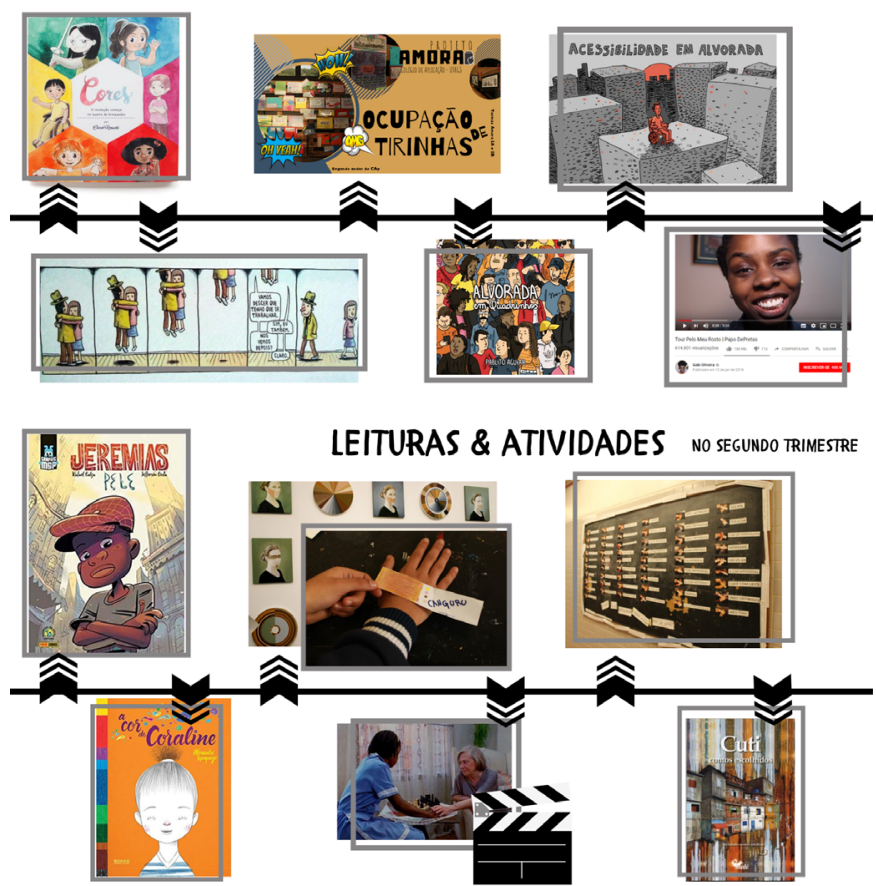

LEITURAS \& ATIVIDADES No TERCERO TRIMESTRE

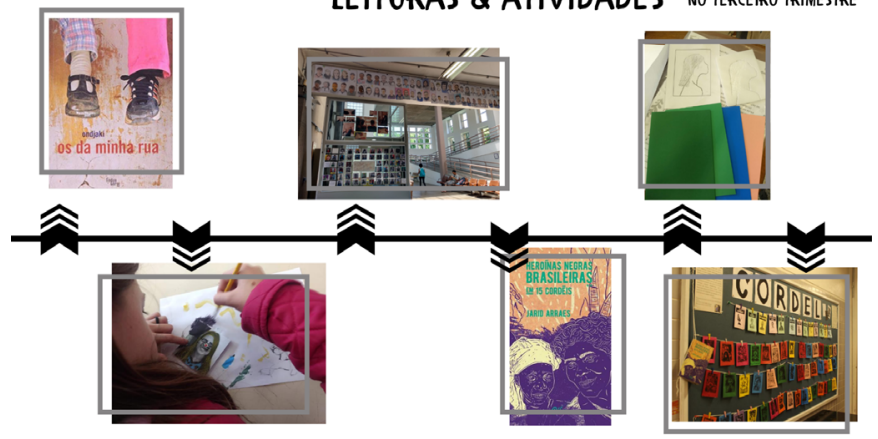

Fonte: Elaborada pelos autores.

Conforme se observa na Figura 1 (que traz uma organização cronológica das ações), o projeto propôs diversificadas atividades, cada uma desenhada a partir de um objetivo específico. Para realizá-las, em alguns

4. A descrição detalhada das etapas está disponível em: https://www.ufrgs.br/prapedi/projetos-vinculados/minha-cor-tua-cor-todas-as-cores/. Em 2019, quando o projeto ainda estava sendo construído, a professora Caroline Valada Becker apresentou uma comunicação na ABRALIC e escreveu o artigo "Minha cor, tua cor, todas as cores: proposição e análise de um projeto de leitura literária" para compor os anais do evento, disponível em: http://www.abralic.org.br/anais/. Queremos destacar, também, que o projeto foi vencedor do Prêmio RBS de Educação: conquistamos o terceiro lugar na categoria escola pública (informações sobre a premiação disponíveis em: http://premiorbsdeeducacao.com.br/). 
momentos, em mais de uma circunstância, professores e professoras das turmas de sexto ano uniam-se, atuando coletivamente; em outros momentos, reunimos especificamente os componentes curriculares Língua Portuguesa e Literatura e Artes Visuais. Na verdade, o vínculo entre Literatura e Artes Visuais deu o tom do projeto pois, como Michèle Petit (2019, p. 32), acreditamos que "com o apoio da literatura associada a outras artes, a capacidade de atenção é refinada, ligações com o próximo e o distante são entretecidas, um lugar é feito para o Outro e talvez para cada um".

Neste artigo, diante das diversificadas etapas e atividades do projeto, destacaremos o trabalho que realizamos com dois gêneros discursivos e literários a partir de duas obras selecionadas: o romance gráfico Jeremias: Pele (Graphic MSP, 2018), com roteiro de Rafael Calça e com desenhos de Jefferson Costa ${ }^{5}$ e o livro Heroinas Negras Brasileiras em 15 Cordéis (2017), de Jarid Arraes.

\section{Estudando narrativa gráfica a partir de Jeremias: Pele}

Nas aulas de Língua Portuguesa e Literatura - seja nos anos finais do Ensino Fundamental, seja no Ensino Médio - e, até mesmo, em provas como vestibulares e ENEM, os quadrinhos estão presentes, geralmente em tirinhas e charges. As histórias em quadrinhos (ou apenas quadrinhos) são, na verdade, um hipergênero ${ }^{6}$, um grande rótulo para delimitar uma linguagem híbrida, cuja principal característica é a união de desenhos e de palavras em uma organização sequencial (RAMOS, 2009, p. 21).

Enquanto produção artística, os quadrinhos têm uma trajetória distinta em cada país e região do mundo, compondo historiografias únicas, ainda que existam aspectos semelhantes. Uma das recorrências refere-se à associação da leitura de quadrinhos à infância. No Brasil, a imagem dos quadrinhos enquanto produção destinada às crianças alimentou, por bastante tempo, a ideia de que HQs seriam leitura pouco exigente, esvaziada de sentidos elaborados e restrita ao entretenimento (nessa circunstância, os quadrinhos foram associados à cultura de massa, o que convoca discussões acerca da atribuição de valor aos bens culturais). Algumas ressalvas preconceituosas diante da leitura de quadrinhos a ser realizada em sala de aula vieram, justamente, dessas reducionistas percepções.

O cenário mudou e, além das tirinhas e das charges, o ensino absorveu, em especial na primeira década do século XXI, as diversas adaptações para quadrinhos de clássicos da literatura nacional e estrangeira - aspecto que fortalece a literatura juvenil enquanto apresentação dos clássicos. Entretanto, devemos lembrar: "Dizer que quadrinhos são uma forma de literatura é uma maneira de usar um rótulo social e academicamente prestigiado - o literário - para validá-los [...]" (VERGUEIRO; RAMOS, 2009, p. 37). E no Brasil, especialmente na última década, o cenário dos quadrinhos consolidou-se (tanto no mercado editorial quanto no meio acadêmico): compreendeu-se que quadrinhos são uma manifestação artística autônoma.

Ainda que as HQs tenham deixado de ser "coisa de criança", Maurício de Sousa e sua Turma da Mônica, voltada ao público infantil, seguem no imaginário dos brasileiros e das brasileiras. O quadrinista, ao perceber as inevitáveis mudanças editoriais e transformações do perfil leitor ${ }^{7}$, por meio de sua produtora, reconfigurou sua criação ${ }^{8}$ de quadrinhos: do formato seriado simples, vendido em banca de jornal (genericamente nomeados "gibis" no Brasil), passou ao mangá Turma da Mônica Jovem (publicada a partir

\footnotetext{
5. O livro foi vencedor do 62ำ Prêmio Jabuti, na categoria História em Quadrinhos (mais informações disponíveis em: https://www.premiojabuti.com.br/premiados-por-edicao/premiacao/?ano=2019).

6. Paulo Ramos (2009, p. 20) usa as ideias de Maingueneau para defender os quadrinhos como hipergênero: “O linguista defende que se trata de um rótulo que daria as coordenadas para a formatação textual de vários gêneros que compartilhariam diversos elementos. O autor cita como exemplo o caso do diálogo, presente em vários gêneros".

7. O termo narrativa gráfica foi construído a partir do campo editorial, pois observa características do objeto livro (formato da edição, público consumidor e, até mesmo, local de venda). Dessa forma, o novo molde editorial fortaleceu a relação dos quadrinhos com outro perfil leitor, extrapolando o âmbito infantil.

8. É importante ressaltar que existe uma equipe trabalhando nos Estúdios Mauricio de Sousa e que diferentes roteiristas e desenhistas realizam o trabalho de criação.

9. O termo relaciona-se à revista Gibi, publicada em 1939
} 
de 2008). Além disso, em 2012, elaborou o projeto Graphic MSP, quando convidou quadrinistas brasileiros para criar novas histórias paras as personagens já clássicas (Mônica, Cascão, Cebolinha...), usando, desta vez, o formato graphic novel. Neste último projeto, conhecemos a obra que compôs o projeto de leitura literária “Minha Cor, Tua Cor, Todas as Cores”, Jeremias: Pele, publicada em 2018.

A partir de agora, as reflexões apresentadas inicialmente neste artigo serão retomadas: as discussões acerca da ERER encontram o mundo ficcional, especificamente uma personagem negra, uma criança. A criação mais famosa de Maurício de Sousa, Turma da Mônica, apresenta aos jovens leitores e às jovens leitoras um grupo de crianças preponderantemente brancas, trazendo apenas um corpo não branco ${ }^{10}$ : Jeremias, personagem não protagonista. Analisarmos essa composição de personagens é imprescindível, uma vez que as representações literárias auxiliam a compor nosso imaginário.

A partir da leitura da dissertação de mestrado Que "negro" é esse nas histórias em quadrinhos? Uma análise sobre o Jeremias de Maurício de Sousa, escrita por Elbert de Oliveira Agostinho, organizamos, abaixo, uma coletânea de representações da personagem Jeremias ${ }^{11}$ : a primeira imagem, de 1970, foi retirada da história “Quem conta um conto”, revista Mônica; a segunda imagem, de 1987, foi retirada da história "Os Novos Donos da Rua"; a terceira imagem, de 1995, foi retirada da revista Cebolinha; a quarta imagem, de 2008, foi publicada na revista Mônica Jovem; por fim, a quinta imagem, de 2018, está na obra Jeremias: Pele.

Figura 2 - A representação da personagem Jeremias ao longo do tempo

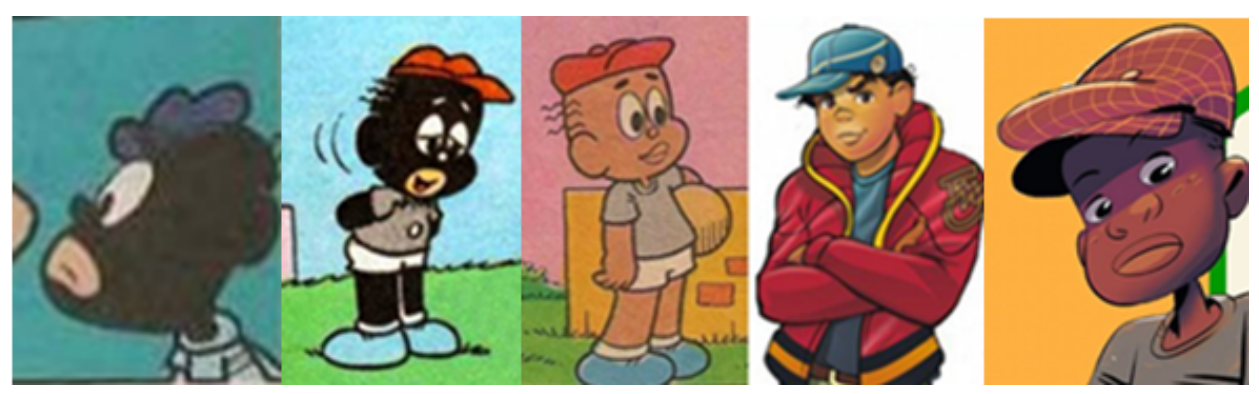

Fonte: Elaborada pelos autores a partir da dissertação de Elbert de Oliveira Agostinho (2017), com o acréscimo da última imagem, retirada do livro Jeremias: Pele.

Por meio dessa compilação, podemos analisar apenas a representação visual, ou seja, literalmente o desenho, verificando traços e cores ${ }^{12}$. A representação física da personagem Jeremias, inicialmente, associa-se à problemática e equivocada construção blackface ${ }^{13}$, a qual desaparece do desenho apenas na década de 90. Na construção da estética do mangá, já nos anos 2000, Jeremias torna-se um não branco de pele mais clara.

Um trabalho de análise detalhada (como o realizado na dissertação referida) verificará quais são as representações da personagem, tendo em vista sua função na narrativa, suas ações, sua linguagem (discursos enunciados), suas relações. Nesse sentido, ao verificarmos a historicidade da personagem Jeremias, destacamos uma publicação na qual ele é protagonista: publicada em 1987, a história “O Príncipe que veio

\footnotetext{
10. A equipe de Maurício de Sousa criou outras personagens negras: Pelezinho e Ronaldinho Gaúcho, "[e]mbora se tratem de dois negros que protagonizam suas próprias revistas, é caso de se questionar se eles foram transformados em personagens de quadrinhos por serem negros ou por serem celebridades esportivas. Questões raciais não são mencionadas em suas histórias" (CHINEN; VERGUEIRO, 2015, p. 80).

11. No final da década de 50, Jeremias surgiu na revista Bidu (Editora Continental), desenhado por Maurício de Sousa, mas não tinha nome; depois passou a integrar a Turma da Mônica (cf. CHINEN, 2019, p. 153).

12. No livro O negro nos quadrinhos do Brasil, Nobu Chinen (2019) organiza um detalhado estudo sobre a representação gráfica da(s) identidade(s) negra(s).

13. Atores brancos pintavam o rosto com tinta preta. Tal "recurso" era associado ao humor e intensificou a representação estereotipada dos corpos negros, no campo artístico, durante muitos anos, pois usava tom grotesco, reforçando e incitando o preconceito.
} 
da África" (revista Turma da Mônica no 5), temos a representação dos escravizados, da ancestralidade, da resistência e uma inscrição da história da escravidão na contemporaneidade ${ }^{14}$.

Quando observamos esse conjunto de criações gráficas, representações de uma personagem negra, compreendemos a potência inerente à publicação Jeremias: Pele - cujos autores, é essencial mencionarmos, são negros. Nessa história, a personagem criança sofre com o racismo estrutural e com o preconceito, contudo, junto com sua família (pais e avô), problematiza o mundo e, mesmo diante das adversidades, orgulha-se de sua negritude e assume postura empoderada (BERTH, 2018): Jeremias, muito jovem, compreende a importância das ferramentas emancipatórias e não silencia diante da estrutura opressora. A cena em que o menino lê um texto diante da turma é evidência desse empoderar-se individual e coletivo. Esse texto é lido em uma aula sobre profissões, em que Jeremias, que sonhava ser astronauta, foi designado pela professora a apresentar a profissão de pedreiro, o que motivou o deboche de seus colegas. Na leitura do texto em que Jeremias apresenta a profissão de pedreiro à turma, o personagem constrói dois questionamentos centrais: a) Por que ele, personagem negro, foi escolhido para apresentar aquela profissão?; b) Por que a profissão de pedreiro é entendida como inferior a tantas outras?

Vamos a uma breve descrição das atividades realizadas com a narrativa em quadrinhos (essa sequência de atividades durou mais de um mês): em sala de aula, em duplas, os e as estudantes realizaram a leitura da obra. Em seguida, conversamos sobre a narrativa, organizando as ideias e tecendo relações com atividades anteriore ${ }^{15}$. Das impressões iniciais (e o livro foi bastante impactante, em especial por se tratar de uma personagem criança), passamos à sistematização do estudo, o que realizamos em duas etapas. Primeiramente, projetamos um conjunto de cenas da $\mathrm{HQ}$, a partir das quais conversamos sobre as situações de racismo representadas no livro; em seguida, relacionamos tais momentos à linguagem dos quadrinhos, desvendando a construção de sentido por meio dos traços, das cores e da organização das páginas.

Para ampliarmos a análise, usamos um roteiro de leitura - o qual, ao invés de simplesmente solicitar a elaboração de uma ficha que contenha nome do autor, lista de personagens e editora, trabalha com situações-problema a serem resolvidas. Para tanto, transcrevemos o texto lido por Jeremias diante de sua turma, e, então, propusemos a tarefa: "Vamos imaginar que você é colega de Jeremias e está diante dele, na sala de aula, ouvindo a leitura do texto transcrito aqui. Agora, vamos pensar: depois de conhecer todas as ideias, opiniões e sentimentos descritos por Jeremias, o que você diria a ele?". Por meio dessa questão (que prevê uma escrita contextualizada em uma situação de comunicação, ainda que imaginária), pretendíamos convocar todos e todas a agir e a exercitar a empatia. Entre outros elementos, trouxemos para esse material as diversas situações de preconceito retratadas no livro; depois de relembrá-las, convocamos todos e todas a refletir sobre a questão: “Se você estivesse lá, o que faria?". Desta vez, em grupos, os e as estudantes debateram e tentaram encontrar soluções, assumindo responsabilidades diante dos problemas sociais.

O material teve, ainda, outros aspectos abordados a partir dos questionamentos dos e das estudantes. Em etapa seguinte, passamos a uma produção textual mais longa e autoral: todos foram convidados a escrever a contracapa do livro Jeremias: Pele, apresentando-o a futuros leitores, o que mobilizou todo o trabalho realizado a respeito da obra e das importantes reflexões que ela proporciona. Depois disso, organizamos, no corredor da escola, uma exposição com esses textos, apresentando Jeremias e convidando a comunidade a ler sua história.

\footnotetext{
14. Nessa breve história em quadrinhos, o avô de Jeremias narra a história de sua família, a qual foi escravizada no Brasil; o príncipe Jeremim (a nomeação "príncipe" é bastante significativa) é representado enquanto resistência, pois luta contra seus senhores; a última cena da obra presentifica as reflexões sobre o sistema escravocrata por meio de uma associação da compra de humanos escravizados à compra de jogadores de futebol.

15. Lembramos que o projeto de leitura é extenso e que Jeremias: Pele é uma das etapas; antes dessa leitura, já havíamos lido muitas tirinhas (circunstância na qual conhecemos as potencialidades da linguagem sequencial) e tínhamos trabalhado detalhadamente o vídeo Tour pelo meu rosto, da youtuber Gabi Oliveira.
} 


\section{Estudando cordel a partir de Heroínas Negras Brasileiras em 15 Cordéis}

De acordo com as informações disponibilizadas pela Academia Brasileira de Literatura de Cordel $(\mathrm{ABLC})^{16}$, a literatura de cordel já existia antes de chegar, por volta do século XVI, à Península Ibérica. No Brasil, o cordel teria chegado primeiramente em Salvador, e depois se espalhado por diversos estados da região Nordeste. No Dossiê de Registro: literatura de cordel (BRASIL, 2018), consta a informação de que a literatura de cordel se inseriu na cultura brasileira por volta do final do século XIX, tendo sua versão escrita originária da oralidade, da poesia musicada por duplas de cantadores de viola, marcada pelo improviso, conhecida como "repente". Entendido como literatura popular, o cordel, quando escrito, era produzido em folhetos que ficavam expostos em cordas (varais), o que explica o nome do gênero. De acordo com Marinho e Pinheiro (2012), os livros, produzidos com material barato, eram comercializados em feiras, praças e mercados.

Por ser um gênero poético que resulta da conexão entre tradições orais e escritas da formação social brasileira, o cordel está vinculado tanto a narrativas orais (contos e histórias de origem africana, indígena e europeia) quanto à poesia (cantada e declamada) e à adaptação para a poesia dos romances em prosa trazidos pelos portugueses (BRASIL, 2018). Além disso, o cordel possui, de acordo com poetas cordelistas, como Monteiro (2002), três elementos definidores: a métrica (conceito associado ao tamanho dos versos em sílabas poéticas), a rima (relação de semelhança entre sons) e a oração (o sentido e a organização da história narrada, que deve ter início, meio e fim).

Tendo se difundido inicialmente no Nordeste, a literatura de cordel atingiu abrangência nacional, sendo inclusive reconhecida como Patrimônio Cultural Brasileiro, em 2018, pelo Conselho Consultivo do Instituto do Patrimônio Histórico e Artístico Nacional ${ }^{17}$. Sua importância como manifestação da cultura brasileira é, por si só, uma boa justificativa para abordá-la nas aulas de Língua Portuguesa e Literatura.

Considerando a vasta produção do gênero no Brasil e a enorme variedade de temáticas desenvolvidas por meio de cordéis, nós, professores e professoras, nos vemos diante da pergunta: que cordéis levar aos e às estudantes? E ainda: como trabalhar cordéis em aula? A partir do eixo temático interdisciplinar que orienta a prática docente aqui relatada, a obra Heroínas Negras Brasileiras em 15 Cordéis, de Jarid Arraes (2017), foi escolhida. A coletânea de cordéis é relevante não só por trazer referências positivas associadas à negritude, mas também por ser protagonizada por mulheres.

Historicamente, a representação das mulheres nos cordéis se deu a partir da perspectiva masculina, o que fez com que prevalecessem, nas obras, estereótipos associados às mulheres, que eram ora retratadas como santas, virgens, puras, recatadas e submissas; ora como lascivas, falsas, demoníacas, adúlteras e traidoras (BRASÍLIA, 2018). Para Oliveira (2017), em seu estudo das representações das mulheres nos cordéis, os cordelistas, para atender a seus próprios princípios morais, revitalizavam arquétipos de narrativas tradicionais que reforçavam estereótipos de virtude e resignação que, há séculos, habitavam o imaginário coletivo. Isso resultava em uma limitada e dicotômica representação da figura feminina, o que deve estar relacionado ao fato de que os homens não só dominaram os meios de produção, como explica Melo (2016), como também definiram as regras de composição e as temáticas que seriam apropriadas para a literatura de cordel. Para a autora, é por esses motivos que as obras entendidas como clássicas do cordel são de autoria masculina e estão alinhadas aos padrões estéticos delineados por concepções do masculino.

Obras como a de Jarid Arraes, por sua vez, estão na contramão da perspectiva que representa a mulher pelo viés masculino. Ao contrário disso, tais obras reconfiguram as representações femininas na produção contemporânea de cordéis. Escolhemos justamente abordar o gênero cordel por esta via: a partir da obra de uma cordelista negra que constrói narrativas sobre mulheres (heroínas) negras.

O trabalho com cordéis, última etapa do projeto "Minha Cor, Tua Cor, Todas as Cores", se iniciou a partir da pergunta aos e às estudantes sobre o que eles sabiam sobre literatura de cordel, para então

\footnotetext{
16. Disponível em: http://www.ablc.com.br/. Acesso em: 5 ago. 2020.

17. Notícia disponível em: http://portal.iphan.gov.br/noticias/detalhes/4833/literatura-de-cordel-e-reconhecida-como-patrimonio-cultural-do-brasil. Acesso em: 5 ago. 2020.
} 
estudar suas características. A leitura coletiva do cordel de Jarid Arraes intitulado "Carolina Maria de Jesus", dedicado a narrar a história da heroína referida no título, esteve presente logo no início do trabalho. Os e as estudantes voluntariaram-se e dividiram-se para ler o cordel em voz alta, na íntegra, para a turma. A escolha pela leitura em voz alta se fundamenta nas características do cordel, que surgiu como literatura oral. Consideramos que a apresentação do gênero deveria se dar desta forma, proporcionando tanto a leitura quanto a escuta do cordel.

O estudo do gênero foi feito, após a primeira experiência de leitura, a partir de perguntas norteadoras, com o intuito de fazer com que os e as estudantes desvendassem suas características. Interessa, em um primeiro momento, fazer com que eles e elas compreendam, da leitura, quem é Carolina Maria de Jesus, por que ela é uma heroína e de que forma sua história está sendo contada. A partir de uma construção coletiva das respostas, devidamente registrada em formato esquemático no quadro e nos cadernos de todas e todos, as características do gênero foram discutidas.

Com o gênero introduzido e as primeiras características desvendadas, diversos cordéis de Jarid Arraes, em formato de folheto, foram distribuídos para a turma. Além do contato com o texto no suporte em que geralmente circula, o folheto, a etapa de leitura de diferentes cordéis possibilita que os e as estudantes, com a mediação do professor, conversem sobre as semelhanças e diferenças entre os cordéis lidos, e destes com aquele lido conjuntamente com a turma. Uma etapa como essa, de investigação a partir da leitura, requer que os conhecimentos mobilizados sejam, novamente, registrados. Além disso, informações sobre a autora, Jarid Arraes, foram compartilhadas com a turma.

A etapa seguinte de estudo do gênero envolveu pesquisa no site da ABLC. Nos computadores do laboratório de informática, os e as estudantes buscaram encontrar respostas para perguntas organizadas em três eixos: a) História do Cordel; b) Cordelistas; c) Estrutura do Cordel. Essa etapa proporcionou, além da aprendizagem de importantes aspectos do gênero, uma reflexão essencial sobre o eixo b: por que só há cordelistas homens na lista de grandes cordelistas do site da $\mathrm{ABLC}^{18}$ ? É interessante notar como a identificação desse problema é possível pelos e pelas estudantes que, nas etapas anteriores do projeto, tiveram momentos para refletir a respeito da noção de representatividade. Ao serem apresentados ao gênero a partir dos cordéis escritos por uma autora, que apresenta histórias de outras mulheres, os e as estudantes não naturalizaram uma concepção masculina da literatura cordel. Causa estranhamento, portanto, não haver nenhuma mulher listada como grande cordelista.

A produção dos cordéis da turma, iniciada após a leitura e o estudo do gênero, foi realizada em etapas. Considerando a leitura dos cordéis de Jarid Arraes, a turma foi convidada a pensar: que histórias queremos contar? Os cordéis de cada um e cada uma deveriam, inspirados nas obras lidas, contar a história de um herói ou de uma heroína. A não delimitação de produzir cordéis sobre mulheres, como faz Jarid Arraes, é, também, uma provocação: depois de tudo o que foi trabalhado, espera-se que os e as estudantes estejam atentos a essa questão. Essa decisão também serve para avaliar o trabalho realizado e descobrir se, por escolha própria, os e as estudantes decidiriam construir narrativas que não fossem somente sobre homens e sobre pessoas brancas.

O primeiro passo da produção foi justamente este: a escolha do herói ou da heroína de cada um(a), considerando que seria preciso uma boa justificativa para a escolha. Aos e às estudantes foi dada a possibilidade de escolher uma pessoa famosa, o que os levaria à etapa de pesquisa a seu respeito; ou uma pessoa que fizesse parte de sua rede de contatos, o que os levaria à etapa de planejamento e realização de entrevista com a pessoa escolhida. Como resultado dessa etapa, diversos heróis e heroínas foram escolhidos, desde familiares próximos aos e às estudantes (mãe e pai, por exemplo) até outras personalidades como Marielle Franco, Nelson Mandela, Malala, Barack Obama, e inclusive a própria autora dos cordéis estudados, Jarid Arraes.

Feitas as pesquisas ou entrevistas com as pessoas que dariam título aos cordéis, os e as estudantes começaram a primeira versão de suas produções. Os cordéis seriam pequenos em extensão (tendo em vista que a proximidade do encerramento do ano letivo impunha restrições de tempo para a conclusão do 
trabalho), sendo constituídos de, no máximo, quatro estrofes, as quais deveriam dar conta de apresentar características importantes da pessoa escolhida e também explicar o motivo de ele ou ela ser um herói ou heroína. O esquema de rimas adotado foi aquele considerado mais frequente entre os cordéis para a ABLC, e também utilizado por Jarid Arraes, a sextilha aberta - construída por estrofes de seis versos em que $o$ segundo, o quarto e o sexto versos rimam (ABCBDB).

Embora a estrutura de rimas da sextilha aberta tenha sido pontualmente estudada em aula, a produção das primeiras versões se mostrou um grande desafio aos e às estudantes. Produzir cordéis implica, afinal, mobilizar diversos recursos linguísticos para garantir que as rimas possam ser construídas. Para organizar a história que se quer contar em um sistema específico de rimas, é preciso que os e as estudantes sejam capazes de fazer uso de estratégias, o que possibilita estudar diferentes níveis da gramática: o fonológico (uma vez que a rima se constitui pela similaridade de sons, o que nem sempre coincide com similaridade de registro ortográfico), o morfológico/morfossintático (a percepção da regularidade de sufixos e de formas verbais é importante para a construção de rimas), o sintático (a manipulação da ordem dos elementos de cada verso pode auxiliar a construção de rimas).

As estratégias para construção das rimas foram construídas durante o momento de produção: à medida em que as dificuldades a partir da prática da escrita surgiam, a reflexão era realizada e ficava registrada no quadro. Além disso, os e as estudantes que primeiro finalizaram seus cordéis foram orientados a ajudar seus pares, o que proporcionou um momento de trabalho colaborativo e também de leitura dos cordéis produzidos pela turma, em que a produção de um(a) estudante-autor(a) inspirava a produção de outro(a).

A dinâmica de escrita e reescrita foi organizada para que cada estudante tivesse a possibilidade de produzir três versões de cada texto - versão inicial, segunda versão e versão final -, sempre contando com comentários realizados pelo professor entre as escritas e as reescritas. A versão final foi digitada e enquadrada em formato produzido pelos professores. A capa do cordel, realizada em parceria com a professora de Artes Visuais que integra o projeto, foi realizada em isogravura, e cada estudante produziu quatro versões (impressões). Por fim, com auxílio dos professores, das professoras e das bolsistas envolvidas no projeto, as quatro versões do cordel de cada estudante foram produzidas, ficando uma delas disponível para leitura em varais dispostos em um dos murais da escola.

Em suma, nosso trabalho com Heroínas Negras Brasileiras em 15 Cordéis e com Jeremias: Pele buscou contemplar o protagonismo positivo de personagens negras para garantir que nossos e nossas estudantes não brancos e não brancas também pudessem se identificar com as obras. Além disso, ao promover que os e as estudantes se colocassem na condição de autores e autoras, o projeto possibilita que seus pontos de vista sejam expressos dentro e fora da sala de aula, fazendo com que eles e elas, protagonistas, atuem no mundo para a solução de problemas. Por fim, não podemos deixar de destacar que o compromisso com a ERER, entendemos, não se esgota na conclusão de um projeto, mesmo que o trabalho seja avaliado como bem-sucedido: ele perdura e merece inserção cotidiana na comunidade escolar.

\section{Considerações finais}

Buscamos, com este artigo, apresentar algumas das propostas pedagógicas que compõem um longo projeto de leitura e escrita desenvolvido com duas turmas de sexto ano em 2019. Não tivemos o intuito de detalhar todas as atividades e abordar todas as etapas do nosso percurso, mas sim de refletir a respeito das práticas de leitura e escrita na Educação Básica e de apresentar caminhos, a partir de nossas experiências e inquietações, para um ensino comprometido com a ERER.

Acreditamos na importância de privilegiar a leitura enquanto experiência, enquanto direito e enquanto alteridade. Destacamos a estreita relação entre escola e política e seus reflexos na educação literária e linguística: porque nossos corpos são atravessados por questões políticas; porque o currículo é atravessado por questões políticas; porque os sujeitos são seres políticos. Dessa forma, ler literatura (diferentes gêneros discursivos) e escrever (de modo contextualizado e motivado) são ações a serem inseridas em práticas sociais 
de letramento conectadas com a realidade. A vida em sociedade, hierarquizada e preconceituosa, convoca os e as docentes a perceberem os atravessamentos políticos inerentes à existência. Daí a necessidade urgente e o compromisso ético de trabalharmos, em sala de aula (e fora dela), com práticas pedagógicas antirracistas. O caminho é longo e a luta é coletiva.

\section{Referências}

AGOSTINHO, Elbert de Oliveira. Que "negro" é esse nas histórias em quadrinhos? Uma análise sobre o Jeremias de Maurício de Sousa. 2017. 184f. Dissertação (Mestrado) - Programa de Pós-Graduação em Relações Étnico-Raciais, Centro Federal de Educação Tecnológica Celso Suckow da Fonseca, Rio de Janeiro, 2017. Disponível em: http://dippg.cefet-rj.br/pprer/attachments/article/81/82_Elbert\%20de\%20Oliveira\%20Agostinho.pdf. Acesso em: 4 ago. 2020.

ARRAES, Jarid. Heroínas Negras Brasileiras em 15 Cordéis. São Paulo: Pólen, 2017.

BERTH, Joice. O que é empoderamento? Belo Horizonte: Letramentos, 2018.

BRASIL. Secretaria de Educação Fundamental. Parâmetros Curriculares Nacionais: terceiro e quarto ciclos do ensino fundamental: língua portuguesa. Brasília, DF: MEC/SEF, 1998.

BRASIL. Ministério da Cultura. Dossiê de Registro: literatura de cordel. Brasília, DF: Iphan/CNFCP, 2018. Disponível em: http://portal.iphan.gov.br/uploads/ckfinder/arquivos/Dossie_Descritivo(1).pdf. Acesso em: 5 ago. 2020.

CALÇA, Rafael; COSTA, Jefferson. Jeremias: Pele. São Paulo: Panini, 2018.

CHINEN, Nobu. O negro nos quadrinhos do Brasil. São Paulo: Peirópolis, 2019.

CHINEN, Nobu; VERGUEIRO, Waldomiro. O negro nas histórias em quadrinhos: discutindo preconceito e resistência em sala de aula. In: NETO, Elydio; SILVA, Marta Regina (org.). História em quadrinhos e práticas educativas, volume II: os gibis estão na escola, e agora? São Paulo: Criativo, 2015.

COLOMER, Teresa. Andar entre livros: a leitura literária na escola. Tradução de Laura Sandroni. São Paulo: Global, 2007.

DALCASTAGNÈ, Regina. A personagem do romance brasileiro contemporâneo: 1990-2004. Estudos de Literatura Brasileira Contemporânea, Brasília, DF, n. 26, p. 13-71, jul./dez. 2005. Disponível em: https://periodicos.unb.br/index. php/estudos/article/view/9077. Acesso em: 2 ago. 2020.

FREIRE, Paulo. Pedagogia do Oprimido. 17. ed. Rio de Janeiro: Paz e Terra, 1987.

GOMES, Nilma Lino. Relações étnico-raciais, educação e descolonização dos currículos. Currículo sem Fronteiras, v. 12, n. 1, p. 98-109, jan./abr. 2012. Disponível em: http://www.curriculosemfronteiras.org/vol12isslarticles/gomes.pdf. Acesso em: 2 ago. 2020 .

KAERCHER, Gládis Elise Pereira da Silva. O mundo na caixa: gênero e raça no Programa Nacional Biblioteca da Escola - 1999. 2005. 225f. Tese (Doutorado em Educação) - Faculdade de Educação, Universidade Federal do Rio Grande do Sul, Porto Alegre, 2005. Disponível em: https://www.lume.ufrgs.br/handle/10183/11831. Acesso em: 2 ago. 2020.

MARINHO, Ana Cristina; PINHEIRO, Hélder. O cordel no cotidiano escolar. São Paulo: Cortez, 2012.

MELO, Miriam Carla Batista de Aragão de. "Cordel de Saia”: autoria feminina no cordel contemporâneo. 2016. 126f. Dissertação (Mestrado em Letras) - Programa de Pós-Graduação em Letras, Universidade Federal de Sergipe, São Cristóvão, 2016. Disponível em: https://ri.ufs.br/handle/riufs/5684. Acesso em: 5 ago. 2020.

MONTEIRO, Manoel. Quer escrever um cordel? Aprenda a fazer fazendo. Campina Grande: Gráfica Martins, 2002.

OLIVEIRA, Letícia Fernanda da Silva. De mártir a meretriz: figurações da mulher na literatura de cordel (1900-1930). 2017. 191f. Dissertação (Mestrado em Letras) - Faculdade de Ciências e Letras de Assis, Universidade Estadual Paulista, Assis, 2017. Disponível em: https://repositorio.unesp.br/handle/11449/149951. Acesso em: 5 ago. 2020.

PETIT, Michèle. Ler o mundo: experiências de transmissão cultural nos dias de hoje. Tradução de Júlia Vidile. São Paulo: Editora 34, 2019.

RAMOS, Paulo. A leitura dos quadrinhos. São Paulo: Contexto, 2009. 
RAMOS, Paulo; FIGUEIRA, Diego. Graphic novel, narrativa gráfica, novela gráfica ou romance gráfico? Terminologias distintas para um mesmo rótulo. In: RAMOS, Paulo; VERGUEIRO, Waldomiro; FIGUEIRA, Diego (org.). Quadrinhos e literatura: diálogos possíveis. São Paulo: Criativo, 2014.

RIBEIRO, Djamila. Pequeno manual antirracista. São Paulo: Companhia das Letras, 2019.

SANTOMÉ, Jurjo Torres. As culturas negadas e silenciadas no currículo. In: SILVA, Tomaz Tadeu da (org.). Alienígenas na sala de aula: uma introdução aos Estudos Culturais em Educação. Rio de Janeiro: Vozes, 1995. p. 159-177.

SILVA, Petronilha Beatriz Gonçalves. Aprender, ensinar e relações étnico-raciais no Brasil. Educação, Porto Alegre, ano 30, v. 63, n. 3, p. 489-506, set./dez. 2007. Disponível em: http://revistaseletronicas.pucrs.br/ojs/index.php/faced/ article/viewFile/2745/2092. Acesso em 2 ago. 2020.

SILVA, Petronilha Beatriz Gonçalves. Crianças negras entre a assimilação e a negritude. Revista Eletrônica de Educação, São Paulo, v. 9, n. 2, p. 161-187, 2015. Disponível em: http://www.reveduc.ufscar.br/index.php/reveduc/article/ view/1137. Acesso em: 2 ago. 2020.

SILVA, Tomaz Tadeu da. Documentos de identidade: uma introdução às teorias do currículo. Belo Horizonte: Autêntica, 2005.

SILVA, Tomaz Tadeu da. O currículo como fetiche: a poética e a política do texto curricular. Belo Horizonte: Autêntica, 1999.

SIMÕES, Luciene et al. Leitura e autoria: planejamento em língua portuguesa e literatura. Erechim: Edelbra, 2012.

VERGUEIRO, Waldomiro; RAMOS, Paulo. Os quadrinhos (oficialmente) na escola: dos PCN ao PNBE. In: VERGUEIRO, Waldomiro; RAMOS, Paulo (org.). Quadrinhos na educação: da rejeição à prática. São Paulo: Contexto, 2009.

Data de submissão: 16/08/2020

Data de aceite: 11/09/2020 